\title{
Singularities: presentation
}

\author{
José M. Aroca · José Cano
}

Received: 14 November 2012 / Accepted: 16 November 2012 / Published online: 2 December 2012 (C) Springer-Verlag Italia 2012

The aim of this (and the next) Special Issue of RACSAM is to collect a set of research papers around singularities of algebraic, analytic and differential equations presented in a congress in Tordesillas (Valladolid, Spain) in honor of the eightieth anniversary of Heisuke Hironaka.

The study of singularities has a long history that goes back to Newton and still been a top subject of research, Hironaka is one of the most important mathematicians of the past century, with strong connections with Spain. Mainly because his influence there are active research teams in singularities in near all the universities of our country, and this publication will be a great support for all those teams.

In his address on the work of Hironaka at the I.C.M. (Nice 1970) Alexander Grothendieck wrote:

Il faut souligner que le problème de la résolution des singularités est loin d'être résolu. En effet, seul le cas de la caractéristique nulle est actuellement réglé. La solution de nombreux problèmes de géométrie algébrique, en caractéristique $p>0$ comme en inégales caractéristiques, dépend de la démonstration d'un théorème analogue pour n'importe quel schéma excellent...Depuis plusieurs années déjà, Hironaka travaille sur le cas de la dimension quelconque. Nul doute que le problème mérite qu'un mathématicien du format de H. Hironaka lui consacre dix ans d'efforts incessants. Nul doute aussi que tous les géomètres lui souhaitent, de tout cour: Bon succès!

J. M. Aroca $(\varangle) \cdot$ J. Cano

C.T.R.I. Uva, Valladolid, Spain

e-mail: aroca@agt.uva.es

J. Cano

e-mail: jcano@agt.uva.es 
Grothendieck is not so good as prophet, ${ }^{1}$ today, not ten but forty two years after his speech, the resolution of singularities over a field of positive characteristic still been an open problem, and Hironaka still working full time in it.

Is important remark that Hironaka is not alone in this work, there are some new ideas, mainly of Hironaka, and some interesting young and not so young people working on these new ideas.

Hironaka believes in the youthfulness as motor of progress in mathematics, as he says:

The development of mathematics consists of leaps and evolution. It's not that scholars with deep experience are of no use, but it's young people who make the leaps.

But at the age of 81 Hironaka still been young and surely will be able to leap over the difficulties of positive characteristic.

Some well known data about Hironaka's biography are the following: Heisuke Hironaka was born in 1931 in Yamaguchi Prefecture, Japan. He graduated from Kyoto University with a bachelor of science in mathematics in 1954, and received his doctorate in mathematics from Harvard University in 1960. Following a lectureship at Brandeis University, Dr. Hironaka was appointed professor of mathematics at Columbia University in 1964, then at Harvard University in 1968. From 1975 to 1988 he also held a professorial post concurrently at Kyoto University. Hironaka was president of Yamaguchi University from 1996 to 2002, and is professor emeritus of Kyoto University and Harvard University. His awards and honors include the Japan Academy Award (1970), Fields Medal (1970), and Order of Culture (1975). Hironaka is a member of the Japan Academy and the American Academy, and is a foreign member of the Académie des Sciences in Paris the Russian Academy of Sciences, and the Real Academia de Ciencias of Spain.

The first thing the name Hironaka suggests is resolution of singularities, and when the people speak about his famous paper of 1964 on resolution of singularities of algebraic varieties in zero characteristic, usually says, with admiration, it is a monumental proof, long and extremely difficult, for instance:

Du point de vue technique, la demonstration du théorème de Hironaka constitue une prouesse peu commune...elle est sans doute l'une des démonstrations les plus dures et les plus monumentales qu'on connaise en mathématique (A. Gothendieck 1970).

Hironaka's proof is one of the longest and hardest in mathematics, and it seems fair to say that only a handful of mathematicians have fully understood it. We are not among them! (E. Bierstone and P. Milman 1997).

But the paper is not only a proof, the paper introduces new techniques and instruments in Algebraic Geometry and Commutative Algebra today universally used. And as happens with the greatest results in Mathematics, once the theorem has been proved, a lot of people begin to work to simplify the proof.

In fact, in the last forty years has been published many new proofs of Hironaka's theorem. The author of one of them J. Kollar says in his introduction:

Two seemingly contradictory aspects make it very interesting to study and develop Hironaka's approach: First the method is very robust, in that many variants of the proof work. One can even change basic definitions and be rather confident that the other parts can be modified to fit Second, the complexity of the proof is very sensitive to details. Small change in definitions and presentation may result in major simplifications (J. Kollar 2007).

Nevertheless in all these new proofs still underline the geometric ideas and instruments created by Hironaka.

1 In the same speech he says about the future of Algebraic Geometry: Cela est d'autant plus vrai que le développement de la géométrie algébrique s'arrêttera court, comme tout le reste, si notre espèce devait disparaìtre dans les prochaines décades, éventualité qui apparaît aujourd'hui de plus en plus probable. 
Hironaka is not only the author of long and difficult papers, he is specially proud of one half-page paper (1962), the shortest never published in Annals of Mathematics, devoted to produced a one-parameter family of non singular compact complex varieties whose special fiber is non-Kähler and all the other fibers are Kähler.

There are substantial contributions of Hironaka to some other fields in Mathematics. For instance:

- Resolution of singularities of complex analytic spaces, developing new techniques in the theory of analytical functions in several complex variables, an his theory of Gardening of infinitely near singularities to overcome the problems of analytic prolongation of blowing-up centers.

- Introduction of the complex analytic analogue of Riemann- Zariski space, the Voûte étoilée.

- A theory of real subanalytic sets, subsets of euclidian space locally finite union of differences of images of semi-analytic sets by proper maps. The main result of the theory is the local reduction, by local blowing-ups of any subanalytic set to a union of cuadrants (Rectilinearization theorem). Using this result Hironaka was first able to prove the triangulability of semi-algebraic sets and finally to prove for subanalytic sets triangulability, Whitney stratification and Lojaseiwcz inequalities. This theory plays a central role in the geometrical study of solution of differentia equations (Tame Geometry).

- A classical theorem of Chevalley and Kakutani proves that two non compact connected Riemann surfaces are conformally equivalent if and only if their algebras of analytic functions are isomorphic as complex algebras, Hironaka under the peudonym of Hej Iss'sa proves that happens if and only if their fields of meromorphic functions are isomorphic.

Hironaka has been also very active in promote mathematical sciences and to bring up young mathematical scientists in several ways, mainly through the foundation JAMS.

JAMS is a foundation established on 1984, its aim is to promote mathematical sciences through research grants and international academic exchange.

The first aim of JAMS is to bring up creative mathematical scientists who could be world leaders in the twenty-first century. There are two different actions:

Over the years, talented young Japanese were sent to universities such as Harvard, Princeton, Yale, Columbia, Duke, UCLA, Oxford, Edinburgh, for graduate study in mathematics, statistics, computer science, mathematical economics, biology and medicine. Aside from them, many other young Japanese were sent overseas for shorter periods for research or study in mathematical sciences.

A summer seminar called "Suuri no Tsubasa" (literally translated as "Wings of Mathematical Sciences"). Each year about fifty talented young students are invited from high-schools and colleges all over Japan (sometimes from overseas, as well). Lectures are given by established research scientists in the forefront, including Nobel laureates, not only in mathematics but also in physics, chemistry, biology, medicine, computer science, engineering, etc. Past participants organized in 1982 an alumni association called "Yugen Club" ("Yugen" means "Puits de Science"). The membership now is around 1,500, they also give lectures on what they are up to, and organize workshops in smaller groups.

As T. Oda remarks:

This is one of the indications of how Professor Hironaka dreams have come true in almost thirty years. Professor Hironaka succeeded in bringing up so many extremely young talents well-versed in mathematical sciences, who not only are active in the forefront, but also will, in turn, keep on bringing up further new generations of talented people. 
As we say before, Hironaka's work to help young people has not been limited to Japan, he has students in several European countries, and his influence in Spain, directly or through his students, is very important. To finish I presented the final part of his speech at the ceremony of his nomination as Doctor Honoris Causa by the Universidad Complutense (Madrid).

Since 1971, I came to Spain, mostly to this university, from time to time whenever I could afford to do so. Each time of my visits, I found some new younger Spanish mathematicians of high aspiration for original research works. In mathematics, as is told by its long history, a new creation is often attained by the talent and energy of the youth.

To conclude my speech on this memorable occasion, $i$ would like to express my personal belief that some day in not too distant future we will see a "siglo de oro en Matemáticas" here in Spain.

Finally we give thanks to the authors who contributed to this Special Issue, to the referees of the papers for his great work, to the scientific comittee of the congress: F. Cano (Valladolid, D. Cutkosky (Missouri), I. Luengo (Madrid), S. Mori (Kyoto) and B. Teissier (Paris) and to the Editor in Chief, M. Lopez Pellicer for his help and patience. Also we want to give thanks to the economical supporters of the congress: Ministerio de Ciencia e Innovación (Spanish Government), Junta de Castilla y León, Programa Consolider and Universidad de Valladolid. 